\title{
OBSERVATIONAL REQUIREMENTS OF GODAE SYSTEMS
}

\author{
Peter R. Oke ${ }^{(1)}$, Magdalena A. Balmaseda ${ }^{(2)}$, Mounir Benkiran ${ }^{(3)}$, James A. Cummings ${ }^{(4)}$, Eric Dombrowsky ${ }^{(3)}$, \\ Yosuke Fujii $^{(5)}$, Stephanie Guinehut ${ }^{(6)}$, Gilles Larnicol ${ }^{(6)}$, Pierre-Yves Le Traon ${ }^{(7)}$, Matthew J. Martin ${ }^{(8)}$ \\ ${ }^{(1)}$ CSIRO/CAWCR (Commonwealth Scientific and Industrial Research Organisation/Centre for Australian Weather and \\ Climate Research), GPO Box 1538, Hobart, Tasmania, 7001,Email: peter.oke@ csiro.au \\ ${ }^{(2)}$ ECMWF (European Centre for Medium-Range Weather Forecasts), Shinfield Park, Reading, RG2 $9 A X$ United \\ Kingdom, Email: Magdalena.Balmaseda@ecmwf.int \\ ${ }^{(3)}$ Mercator Ocean, 8-10 rue Hermès, 31520 Ramonville Saint Agne, France, \\ Email: Mounir.Benkiran@mercator-ocean.fr, Eric.Dombrowsky@mercator-ocean.fr \\ ${ }^{(4)}$ Oceanography Division, NRL Naval Research Laboratory, Monterey, CA 93943, USA, \\ Email: cummings@nrlmry.navy.mil \\ ${ }^{(5)}$ MRI (Meteorological Research Institute), 1-1 Nagamine, Tsukuba, Ibaraki, 305-0052, Japan, \\ Email:yfujii@mri-jma.go.jp \\ ${ }^{(6)}$ CLS (Collecte, Localisation, Satellites)-Space Oceanography Division, 8-10, rue Hermès, Parc Technologique du \\ Canal, 31520 Ramonville Saint-Agne, France, Email: Stephanie.Guinehut@cls.fr, Gilles.Larnicol@cls.fr \\ (7) IFREMER (French Institute for Exploitation of the Sea/Institut Français de Recherche pour l'Exploitation de la Mer), \\ Technopole de Brest-Iroise, B.P. 70 29280, Plouzané France, Email: Pierre.Yves.Le.Traon@ifremer.fr \\ ${ }^{(8)}$ Met Office, FitzRoy Road, Exeter, United Kingdom, Email: matthew.martin@metoffice.gov.uk
}

\begin{abstract}
Global ocean forecast systems, developed under the Global Ocean Data Assimilation Experiment (GODAE), can be used to assess the impact of different components of the Global Ocean Observing System (GOOS). GODAE systems can be exploited to help identify observational gaps and to ultimately improve the efficiency and effectiveness of the GOOS for constraining ocean models for ocean prediction and reanalysis. Many tools are currently being used by the GODAE community to evaluate the GOOS. Observing System Experiments, where different components of the GOOS are systematically withheld, can help quantify the extent to which the skill of a model depends on each observation type. Various other techniques, including observing system simulation experiments, adjoint- and ensemble-based approaches, can be used to aid the design and evaluation of ocean observing systems. A suite of examples using these methods to evaluate the GOOS from a GODAE perspective is presented in this paper. Also included in this paper is a proposed plan to move these activities towards routine monitoring of the GOOS using operational GODAE systems.
\end{abstract}

\section{INTRODUCTION}

The development of operational ocean forecast systems is a key initiative of the Global Ocean Data Assimilation Experiment (GODAE). All GODAE systems are underpinned by the Global Ocean Observing System (GOOS; www.ioc-goos.org) that is comprised of satellite altimetry, satellite sea surface temperature (SST) programs, delivered through the GODAE High Resolution SST effort (GHRSST; www.ghrsst-pp.org), and in situ measurements from the Argo program, the tropical moored buoy, surface drifting buoys, XBT (Expendable Bathythermographs) and tide gauge networks. Each of these observation programs are expensive and require a significant international effort to implement, maintain, process and disseminate. While many components of the GOOS are primarily intended for climate applications, their application to operational ocean forecast systems is important. In this paper, we present results from analyses that seek to assess the benefits of different observation types and arrays to realistic ocean forecast and reanalysis systems using Observing System Experiments (OSEs) and Observing System Simulation Experiments (OSSEs).

OSEs generally involve the systematic denial of different observation types from a data-assimilating model in order to assess the degradation in quality of a forecast or analysis when that observation type is not used. Importantly, the impact of each observation depends on the details of the model, assimilation method and error estimates employed.

OSSEs often involve some sort of twin experiment, where a model is sampled in a way that resembles real observations, and those observations are assimilated into an alternative model. Similarly, ensemble- and adjoint-based methods for observing system design and assessment, often do not use real observations, but instead diagnose properties of a model to identify regions of high sensitivity and influence. These types of analyses, though idealised, may be used to assess the impact of hypothetical observations that may not exist yet, and therefore contribute to the design of future observing systems.

The inaugural Ocean Observing Panel for Climate (OOPC) - GODAE meeting on OSSEs and OSEs was held at UNESCO/IOC (United Nations Educational Scientific and Cultural Organization/International 
Oceanographic Commission in Paris, France in November 2007 (www.godae.org/OSSE-OSEhome.html). This was the first international meeting dedicated to the subject of observing system evaluation using GODAE systems. Many of the ideas and results presented in this paper are based on presentations from the OOPC-GODAE OSSE/OSE meeting. Other recent reviews that provide an assessment of the GOOS for constraining data assimilating ocean models include [1], [2] and [3].

\section{OBSERVING SYSTEM EXPERIMENTS}

A determination of the requirements of the GOOS for operational oceanography is the primary goal of the studies described in this section. Collectively, we seek to assess the importance of different observation types for meeting the needs of operational systems, including observation-based mapping systems, like that of CLS/AVISO (Collective Localisation Satellites/Archiving, Validation and Interpretation of Satellite Oceanographic data), short-range prediction systems from GODAE partners (e.g. BLUElink (Ocean forecasting Australia), Mercator, NRL (Naval Research Laboratory), UK Met Office, TOPAZ (Towards an Operational Prediction system for the North Atlantic European coastal Zones)), and seasonal prediction (e.g. ECMWF (European Centre for Medium-Range Weather Forecasts), JMA (Japan Meteorological Agency), POAMA (Predictive Ocean Atmosphere Model for Australia)).

\subsection{Number of altimeter missions}

The Ssalto/Duacs (Segment Sol multi mission d'Altimétrie, d'Orbitographie et de localisation précise/ Developing Use of Altimetry for Climate Studies) center has led several studies aiming to identify the most appropriate satellite configuration to observe the mesoscale ocean. Focusing first on the Mediterranean Sea, and later on the global oceans, [4 [ and [5] have demonstrated the benefits of merging data from four altimeter missions to produce high-resolution maps of sea level anomalies (SLA). For example, [4] show that in areas of intense variability, the root-mean-squared (RMS) differences between a classical configuration of two altimeters (Jason-1+ERS-2 (European RemoteSensing Satellite)/Envisat (Environmental Satellite)) and the scenario merging data from four altimeters can reach $10 \mathrm{~cm}$ for SLA and $400 \mathrm{~cm} 2 / \mathrm{s} 2$ for EKE (eddy kinetic energy) (derive from SLA-based estimates of geostrophic velocities). This represents a significant percentage of the signal variance. At mid- and highlatitudes, previous studies have also shown a clear underestimation of EKE due to the under-estimated high frequency and high wavenumber signals produced when data from only two altimeters are used [6], [7] and [8].

The impact of four altimeters is expected to be particularly important for operational forecast and analysis systems. Reference [9] quantifies the degradation in the quality of the altimeter products when Near-Real-Time (NRT) data are used compared to when Delayed-Time (DT) data are used. Three main sources of errors are identified in NRT data: the orbit is less accurate; the latency of data is a problem; and observation windows necessarily favour "old" data for NRT systems. Validation with independent in-situ data demonstrates the degradation of NRT maps compared to DT maps (Table 1). This shows that 4 altimeters in NRT are needed to get the same performance as 2 altimeters in DT. The statistics in Tab. 1 show comparisons between SLA from tide gauges and SLA maps. Table 1 includes results using an old and new DT data set and demonstrates the importance of continuous advances in the processing of altimeter data.

\begin{tabular}{|c|c|c|c|}
\hline Variable & $\begin{array}{c}\text { Old } \\
\text { Delayed- } \\
\text { Time }\end{array}$ & $\begin{array}{c}\text { New } \\
\text { Delayed- } \\
\text { Time }\end{array}$ & $\begin{array}{c}\text { Near-Real- } \\
\text { Time }\end{array}$ \\
\hline $\begin{array}{c}2 \\
\text { missions }\end{array}$ & 4.72 & 4.26 & 4.82 \\
\hline $\begin{array}{c}4 \\
\text { missions }\end{array}$ & 4.27 & 3.94 & 4.42 \\
\hline
\end{tabular}

Table 1: RMS difference (in $\mathrm{cm}$ ) between tide gauge sea-level and mapped altimetry for the old delayed-time, the new delayed-time and the near-real-time system; adapted from [9]. Comparisons are for the period October 2002 - August 2003.

A series of OSEs, using the Mercator Ocean forecasting system in the North Atlantic Ocean and the Mediterranean Sea has been conducted by [10] to evaluate the impact of data from multiple altimeter missions on the forecast skill over 7-days. This system assimilates along-track altimeter data, SST and in situ profiles using a multivariate OI (Optimal Interpolation) scheme. Specifically, [10] sought to assess the degradation in the forecast skill when the number of altimeters is varied. They performed several 6-month simulations in which they assimilated all available SST and T/S (Temperature/Salinity) profiles and altimeter data from 0 to 4 altimeters (T/P (TOPEX/Poseidon), Jason-1, Envisat and GFO (Geosat Follow-On). The OSEs were conducted during the tandem T/P and Jason1 missions in 2004-2005 when data from 4 altimeters were available. Figure 1 summarises their results, showing the degradation of the system skill, when data from $0,1,2$ and 4 altimeters are assimilated. The estimated degradation, presented as a percentage of the observed variability, is relative to an OSE that assimilates data from 3 altimeters (Jason-1, Envisat and GFO; so positive degradation is worse and negative is better than 3 altimeters). When no altimeter data are assimilated, there is effectively no predictive skill at the mesoscale. Conversely, Figure 1 suggests that some 
skill is added to the Mercator system when data from 4 altimeters are assimilated, instead of just 3 . These results are consistent with those presented by [4].

Clearly, the addition of the first altimeter has the greatest impact on forecast skill (Figure 1) - and there are diminishing returns from each additional altimeter. However, the benefits of additional altimeters are likely to be at smaller and smaller scales, as higher spatial and temporal resolution is resolved. We note that these small mesoscale features are important for many endusers of GODAE products (e.g., search and rescue, oil spill mitigation and so on).

Reference [10] conducted their OSEs in a real-time context. That is, they performed OSEs to produce nowcasts under realistic conditions, excluding missing data due to latency of data availability. They produce 7day forecasts that are initialised with each nowcast and also hindcasts, using all available data. Table 2 summarises their results, showing that if only SST and in situ T/S are assimilated (i.e., no altimetry) the error is large (up to $\sim 13 \mathrm{~cm}$ RMS). Note also that to obtain error levels equivalent to the hindcast with only one altimeter, data from 4 (2) altimeters are needed to produce forecast (nowcasts) of equivalent skill under realistic conditions. These results are consistent with the conclusions of [9] who found that 4 altimeters in NRT is equivalent to 2 altimeters in DT.

\begin{tabular}{|l|c|c|c|c|c|}
\hline $\begin{array}{l}\text { SLA } \\
\text { RMS } \\
\text { diff }\end{array}$ & No alt & J1 & $\begin{array}{c}\text { J1 + } \\
\text { Env }\end{array}$ & $\begin{array}{c}\text { J1 + } \\
\text { Env }+ \\
\text { GFO }\end{array}$ & $\begin{array}{c}\text { J1 + } \\
\text { Env + } \\
\text { GFO + } \\
\text { T/P }\end{array}$ \\
\hline $\begin{array}{l}7 \mathrm{~d} \\
\text { frcst }\end{array}$ & & 10.27 & 9.67 & 8.95 & 8.62 \\
\hline Nwcst & & 9.15 & 8.36 & 7.50 & 7.08 \\
\hline Hndest & 12.94 & 8.38 & 7.07 & 6.18 & 5.63 \\
\hline
\end{tabular}

Table 2: RMS of the difference (in $\mathrm{cm}$ ) between Jason-1 observation and 7-day forecast, Nowcast (real-time analysis) and hindcast (best analysis) for several OSES where altimeter data from 0, 1, 2, 3 and 4 satellites are assimilated; adapted from [10].

Results from a series of OSEs designed to assess the impact of different numbers of altimeters using the UK Met Office system are presented in Figure 2. They use the $1 / 9^{\circ}$ North Atlantic FOAM (Forecasting Ocean Assimilation Model) configuration together with an OIbased method of assimilation [11], and run a series of three-month integrations beginning in January 2006. The impact of different numbers of altimeters are assessed by comparing the modelled SLA with the assimilated along-track altimeter data, and comparing the modelled surface velocities with those derived from surface drifting buoys (which are not assimilated).
These results quantify the improvements when 1,2 and 3 altimeters are added to the assimilated observations. The addition of the first altimeter seems to have the most impact. The results are different for

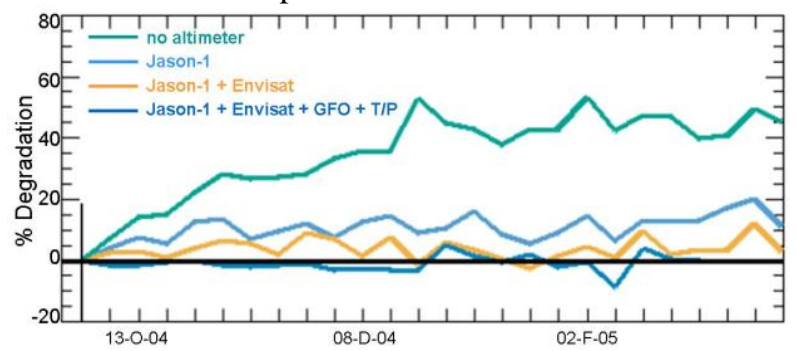

Figure 1: Normalised measure of 7-day forecast error in the North Atlantic, when no altimeter data are assimilated and when data from 1, 2 and 4 altimeters are assimilated. Forecast skill is measured against the forecast error when Jason+Envisat $+G F O$ data are assimilated (REF; see equation (1)). A positive \% implies a degradation of the forecast skill, $O$ is the baseline and negative means an improvement; adapted from [10]).
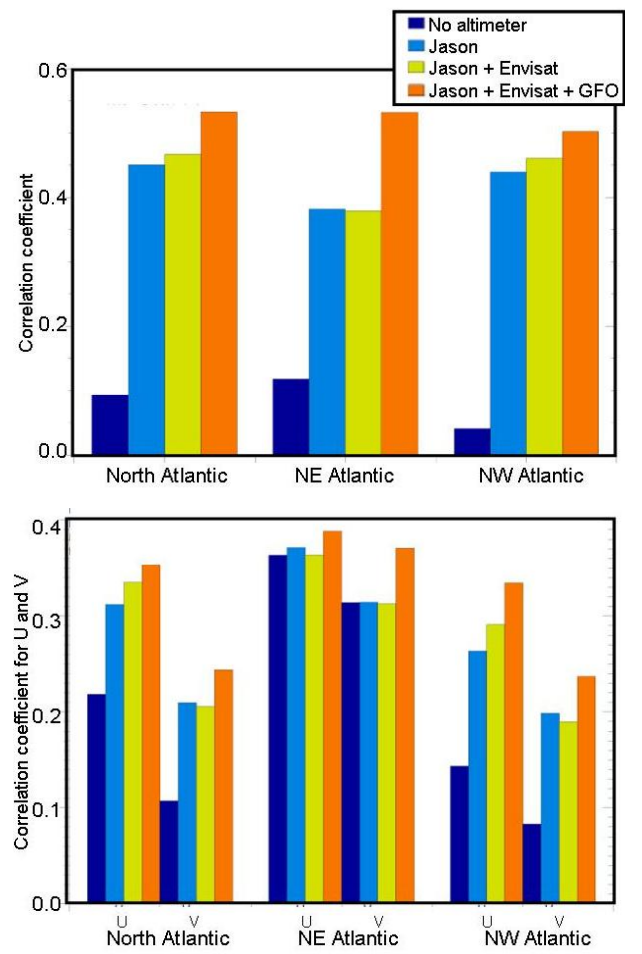

Figure 2: Anomaly correlation between forecast (top) SLA and along-track altimetric SLA from all satellites and (bottom) forecast near-surface velocity and nearsurface velocity derived from drifting buoys; based on a series of OSEs that assimilate SLA data from drifting buoys; based on a series of OSEs that assimilate SLA data from 0-3 satellites, using the $1 / 9^{\circ}$ North Atlantic FOAM configuration [11] for the first 3 months of 2006.

different regions; surface velocities in the northeast Atlantic are better than surface velocities in the northwest Atlantic. This indicates that the mesoscale 
dynamics in the northeast are better constrained by the altimeters than in the north-west. The difference in the quality of surface winds in different regions probably has a significant influence on the quality of the modelled surface velocities.

\subsection{Impact of different data types}

Using the Bluelink forecast system, [12] performed a series of OSEs to compare the relative impact of Argo, SST and SLA observations on an eddy-resolving ocean reanalysis; they systematically withheld altimeter, Argo and SST observations. Their results highlight the complimentary nature of the different observation types. For example, satellite SST observations are the only observation type considered that have the potential to constrain the circulation in shallow seas and over wide continental shelves; altimetry is the only observation type that even goes close to constraining the mesoscale ocean circulation (Figure 3); and Argo observations are the only observation type that constrains sub-surface temperature and salinity. Their results indicate that while there is some redundancy for representing broadscale circulation, all observation types are required for constraining mesoscale circulation models.

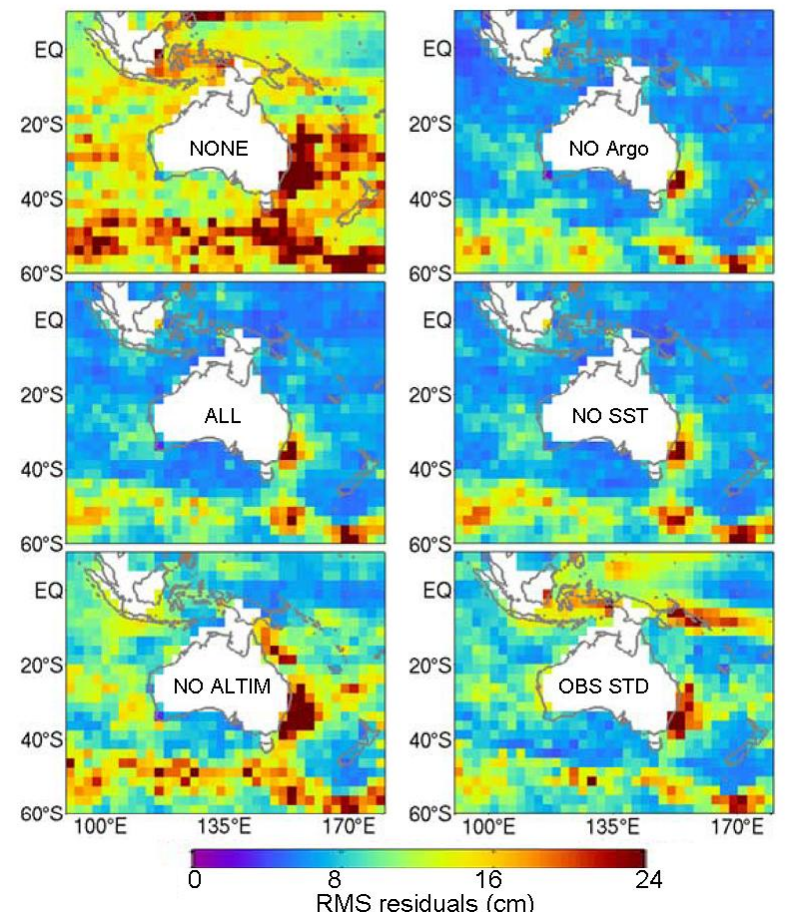

Figure 3: RMS residuals between observed and modelled SLA for each OSE, and the observed standard deviation. Statistics are computed using along-track SLA observations from Jason-1, Envisat, and GFO for the period January-May 2006; adapted from [12].

The impact of the different components of the GOOS on ECMWF seasonal forecast system has been assessed through a series of OSE studies [13], [14] and [15]. Reference [13] focussed on the relative impact of the tropical in situ mooring arrays, XBTs and Argo observations for a period when Argo array was incomplete, and when altimeter data was not assimilated. reference [14], used an improved version of the system [16] that assimilated both salinity and altimeter data are assimilated and showed the significant positive impact of Argo observation. In the most recent series of OSE experiments using the ECMWF system, [15] assess the relative contribution of Argo, altimeter and moorings to the skill of seasonal forecast through a series of OSEs. The results demonstrate that Argo, altimeter and mooring observations contribute to the improvement of the skill of seasonal forecasts of SST. For example, they demonstrate that assimilation of Argo observations are particular beneficial to SST forecasts in the eastern tropical Pacific, altimeter data are particularly beneficial to the central Pacific and the north subtropical Atlantic and that mooring data have a significant positive impact on forecast skill across the entire tropical Pacific. The positive impacts of Argo and mooring data on the forecast skill of SST in seasonal forecasts are also confirmed in JMA's system [17].

A series of OSEs using the Global Observed Ocean Products [18] that combine remotely-sensed (SLA, SST) and in situ observations, using the method described by [19], facilitates a quantitative assessment of the relative contributions from different components of the GOOS. Figure 4 shows the RMS errors of subsurface temperature (T) and salinity (S) using this approach. This demonstrates that more than $40 \%$ of the temperature signal can be reconstructed at depth from remotely-sensed data using a simple statistical method and that the complementary use of in situ measurements (denoted combined fields in Figure 4) improves the estimation by an additional 10$20 \%$.
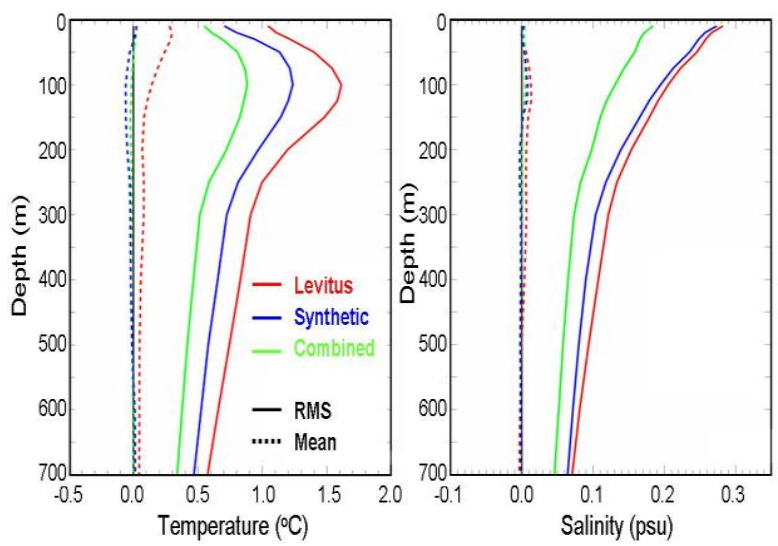

Figure 4: RMS (solid lines) and mean (dotted lines) error in predicting sub-surface temperature (left) and $S$ (right) anomalies using Levitus monthly mean climatology (red), synthetic fields (blue), combined fields (green); adapted from [18]. 


\section{OBSERVING SYSTEM SIMULATION EXPERIMENTS}

The potential impact of the assimilation of remotely sensed sea surface salinity (SSS) observation from SMOS (Soil Moisture and Ocean Salinity) or Aquarius on the forecast skill of the Mercator Ocean system has been assessed by [20] through a series of OSSEs. They conclude that the level of observation error will have a critical impact on the value of this new observation type to GODAE systems. This is consistent with those of [21] who assessed the theoretical impact of SSS observations on an ensemble-based data assimilation system.

Several different techniques have been used together with GODAE systems to contribute to the design of ocean observation programs. These include OSSEs that assess specific pre-determined design options [22] and [23] and techniques that objectively generate "optimal" observation arrays. The latter includes Kalman filter techniques [24], ensemble approaches [25] and adjoint and representer-based methods [26], [27] and [28]. Some of the studies referred to above have contributed to the design to assessment of the Argo array; some have assessed the design of tropical mooring arrays; and others have identified regions that may help constrain model variability in western boundary currents. OSSE activities, while often somewhat theoretical, have contributed to discussions of the design of oceanographic observation programs.

\section{EMERGING TECHNIQUES}

To date, observing system evaluation activities conducted under GODAE, and related programs, have typically employed conventional methods including OSEs and OSSEs, as described above. These activities have been designed to assess the limitations of the GOOS for GODAE applications (including forecast, reanalysis and analysis systems). These have typically involved OSEs that are performed several years after observations are collected (e.g., during periods when data from 4 altimeters were available and when the Argo program was still incomplete). However, we recognise that the GOOS is constantly changing. The significance of the completed OSEs is therefore increasingly irrelevant to the observational community. To have a real impact, the GODAE OceanView community is collectively shifting their efforts to transition their OSE/OSSE activities towards routine monitoring of the GOOS. Some initial steps have been taken to coordinate these activities. Specifically, agreement is sought on how GODAE partners can and should move towards routine monitoring of the GOOS; agreement on how this can be coordinated between the international groups; and a staged plan for moving these activities towards routine monitoring, so that the
GODAE OceanView community can have a real impact on the ongoing design and assessment of the GOOS.

Emerging techniques under consideration by GODAE include analysis and forecast sensitivity experiments. These represent diagnostics from analysis and forecasts systems that are relatively inexpensive to compute. Analysis sensitivity experiments seek to quantify the impact of each individual observation on an analysis [29]. Similarly, an adjoint technique can quantify the sensitivity of a forecast to assimilated observations [30].

Diagnostics derived from analysis sensitivity include the information content (IC) of each observation and the degrees of freedom of signal (DFS). These quantify the impact of each observation on an analysis, given the assumed errors, length-scales etc, in the data assimilation being used. A preliminary example of the IC and DFS for different observation types on the Bluelink reanalysis system [1] is given in Figure 5. Based on these results, it appears that both altimetry and SST observations are well used by the Bluelink system. However, information from the Argo data is either not extracted by the Bluelink system in an optimal way, or is somewhat redundant - possibly well represented by the other assimilated observations. At this stage of development, the former explanation seems most likely. By producing these, and other, diagnostics from a number of GODAE systems, it is anticipated that the true value of all observations for GODAE systems can be routinely monitored and quantified. In turn, these evaluations could be fed back to the broader community for consideration.

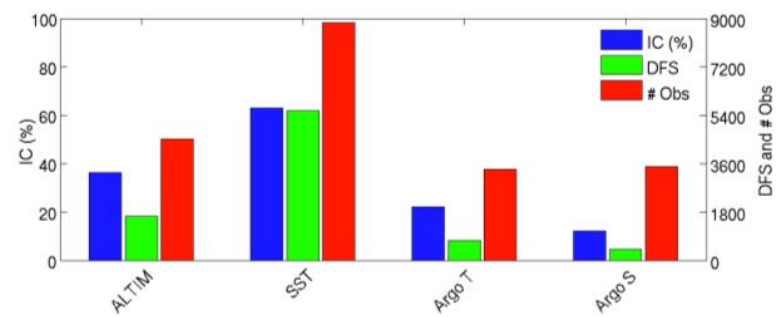

Figure 5: Preliminary estimates of the Information Content (IC; \%), degrees of freedom of signal (DFS) and the number of assimilated super-observations (\# Obs) for the Bluelink reanalysis system in the region 90 $180^{\circ} \mathrm{E}, 60^{\circ} \mathrm{S}$-equator, computed for 1 January 2006. The scale for the IC is to the left and the scale for the DFS and \# Obs is to the right.

\section{CONCLUSIONS}

The purposes of this paper is to summaries the OSE/OSSE activities conducted under GODAE, and related programs, to document some of the key results and to describe how these activities may progress under GODAE OceanView in the future.

One recurring result from different OSEs includes the apparent complimentary nature of different observation 
types [19], [18], [21] and [2]. This means that none of the observation types in the GOOS is redundant. Each different observation type brings unique contributions to the GOOS and all observation types should be routinely assimilated by forecast and reanalysis products; and more importantly maintained by the international community.

Another result that is common to many studies is the necessity of assimilation of altimeter data to represent mesoscale variability [12], [11], [9] and [31]. Moreover, a couple of studies demonstrated that for NRT applications data from 4 altimeters is needed to obtain errors that are comparable to systems using 2 altimeters in delayed-mode [9] and [31].

Several studies have demonstrated the importance of Argo observations. These include several OSE and OSSE studies based on analysis systems [19] and [18] and OSEs based on both short-range and seasonal prediction systems [12], [16] and [17]. Several of these studies specifically noted that Argo is the only observation platform that provides global-scale information for constraining salinity.

All GODAE forecast systems considered in this paper include SST observations as an essential core data set. Indeed, one could argue that in many coastal regions and shallow seas, SST is the only observation type that adequately monitors ocean properties. The consistent uptake of SST observations is a credit to the GHRSST program that provides high-level quality controlled SST data in NRT.

The versatility of OSSEs and variational data assimilation techniques are also demonstrated in this paper, where it is shown that insight into observing strategies for resolving specific processes, like the Kuroshio meander [27], and specific time-scales of variability [25] can be gained. The impact of new observation types, like surface salinity observations, has also been assessed, with promising results [20] and [21].

We note that many groups from the NWP community routinely provide statistics on data impacts; in some cases - every day for every assimilation cycle. The methods discussed in sections 2 and 3 of this paper (OSE and OSSEs) are very expensive - and as a result are not applied routinely. They are also, arguably, of limited value. For example, they will not automatically identify the impacts of changes in the Argo array - as the total number of Argo floats fluctuates and their spatial distribution changes. By contrast, as the NWP community have demonstrated, the routine application of computationally efficient methods, such as those referred to in section 4 can readily be applied to operational systems in NRT - and can potentially support the maintenance and development of the GOOS on an ongoing basis. Following the lead of the NWP community, during the new sustained phase of GODAE, so called GODAE OceanView, a coordinated effort is planned for OSE/OSSE activities to move towards the routine monitoring of the GOOS using GODAE systems.

\section{ACKNOWLEDGEMENT}

The participants of the OOPC-GODAE meeting on OSSEs and OSEs, UNESCO/IOC, Paris, France in November 2007 are gratefully acknowledged for their contributions to this work. The following organisations and agencies are acknowledged for their financial support: Bureau of Meteorology; CSIRO (Commonwealth Scientific and Industrial Research Organisation); European Space Agency (ESA); French Space Agency (CNES (Centre National d'Études Spatiales)); French Service Hydrographique Océanographique de la Marine (SHOM); Japan Meteorological Agency; the Japanese Ministry of Education, Culture, Sports, Science and Technology; Office of Naval Research; and the Royal Australian Navy. Satellite altimetry is provided by NASA (National Aeronautics and Space Administration), CNES and NOAA (National Oceanic and Atmospheric Administration) and SST observations are provided by NOAA. Argo data are provided by the Coriolis and USGODAE data centres.

\section{REFERENCES}

1. Oke, P. R., \& Co-Authors (2008) Observing System Evaluation, Proceedings of the GODAE Final Symposium, Nice, France, 192-209.

2. Oke, P. R., \& Co-Authors (2009) Observing System Evaluations using GODAE systems, Oceanography, 22(3), 144-153

3. Heimbach, P. \& Co-Authors (2010). "Observational Requirements for Global-Scale Ocean Climate Analysis: Lessons from Ocean State Estimation" in these proceedings (Vol. 2), doi:10.5270/OceanObs09.cwp.42

4. Pascual A., Faugère, Y., Larnicol, G. \& Le Traon. P.-Y. (2006) Improved description of the ocean mesoscale variability by combining four satellite altimeters, Geophysical Research Letters, 33, doi:10.1029/2005 GL024633.

5. Pascual A., Pujol, M. I., Larnicol, G., Le Traon, P.-Y. \& Rio, M.-H. (2007) Mesoscale Mapping Capabilities of Multisatellite Altimeter Missions: First Results with Real Data in the Mediterranean Sea. Journal of Marine Systems, 65, 190-211.

6. Ducet, N., Le Traon, P.-Y. \& Reverdin, G. (2000) Global high-resolution mapping of ocean circulation from TOPEX/Poseidon and ERS-1 and -2. Journal of Geophysical Research, 105, 19477-19498.

7. Le Traon, P.-Y. \& Dibarboure, G. (2002) Velocity mapping capabilities of present and future altimeter 
missions: The role of high frequency signals. Journal of Atmospheric and Oceanic Technology, 19, 2077-2088.

8. Brachet S., Le Traon, P.-Y. \& Le Provost, C. (2004) Mesoscale variability from a high-resolution model and from altimeter data in the North Atlantic Ocean. Journal of Geophysical Research, 109(C12025), doi:10.1029/2004JC002360.

9. Pascual A., Boone, C., Larnicol, G., \& Le Traon, P.-Y. (2008) On the quality of real time altimeter gridded fields: comparison with in situ data, Journal of Atmospheric and Oceanic Technology, doi:10.1175/2008JTECHO556.1.

10. Benkiran, M., \& Co-Authors (2008) Impact study of the number Space Altimetry observing systems on the altimeter data assimilation in the Mercator-Ocean system. In preparation.

11. Martin, M.J., Hines, A. \& Bell, M. J. (2007) Data assimilation in the FOAM operational short-range ocean forecasting system: a description of the scheme and its impact. Quarterly Journal of the Royal Meteorological Society, 133, 981-995.

12. Oke, P.R., \& Schiller, A. (2007) Impact of Argo, SST and altimeter data on an eddy-resolving ocean reanalysis. Geophysical Research Letters, 34(L19601), doi:10.1029/2007GL031549.

13. Vidard, A., Anderson, D. \& Balmaseda, M. A. (2007) Impact of ocean observation systems on ocean analysis and seasonal forecasts, Monthly Weather Review, 135, 409-429.

14. Balmaseda, M. A., Anderson, D. \& Vidard, A. (2007) Impact of Argo on analyses of the global ocean. Geophysical Research Letters, 34(L16605), doi:10.1029/2007GL030452.

15. Balmaseda, M. A., \& Anderson, D. (2009) Impact of initialization strategies and observations on seasonal forecast skill. Geophysical Research Letters, 36(L01701), doi:10.1029/2008GL035561.

16. Balmaseda, M. A., Vidard, A. \& Anderson, D. (2008) The ECMWF ORA-S3S ocean analysis system. Monthly Weather Review, 136, 3018-3034.

17. Fujii, Y., Yasuda, T., Matsumoto, S., Kamachi M. \& Ando, K. (2008) Observing System Evaluation (OSE) using the El Niño forecasting system in Japan Meteorological Agency. Proceedings of the oceanographic society of Japan fall meeting (in Japanese).

18. Larnicol, G., \& Co-Authors (2006) The Global Observed Ocean Products of the French Mercator Project, Proceedings of 15 Years of progress in radar altimetry Symposium, ESA Special Publication, pp. 614.

19. Guinehut, S., Le Traon, P.-Y., Larnicol G. \& Phillips, S. (2004) Combining Argo and remote-sensing data to estimate the ocean three-dimensional temperature fields - a first approach based on simulated observations. Journal of Marine Systems, 46, 85-98.
20. Tranchant, B., \& Co-Authors (2008) Expected impact of the future SMOS and Aquarius ocean surface salinity missions in the Mercator Ocean operational systems: new perspectives to monitor ocean circulation. Remote Sensing of Environment, 112, 1476-1487.

21. Brassington, G. B., \& Divakaran, P. (2009) The theoretical impact of remotely sensed sea surface salinity observations in a multi-variate assimilation system. Ocean Modelling, 27, 70-81.

22. Guinehut, S., Larnicol, G. \& le Traon, P.-Y. (2002) Design of an array of profiling floats in the North Atlantic from model simulations. Journal of Marine Systems, 35, 1-9.

23. Schiller, A., Wijffels, S. E. \& Meyers, G. A. (2004) Design requirements for an Argo float array in the Indian Ocean inferred from observing system simulation experiments. Journal of Atmospheric and Oceanic Technology, 21, 1598-1620.

24. Ballabrera-Poy, J., Hackert, E., Murtugudde, R., \& Busalacchi, A. J. (2007) An observing system simulation experiment for an optimal moored instrument array in the tropical Indian Ocean. Journal of Climate, 20, 32493268 .

25. Sakov, P., \& Oke, P. R. (2008) Objective array design: Application to the tropical Indian Ocean. Journal of Atmospheric and Oceanic Technology, 25, 794-807.

26. Vecchi, G.A. \& Harrison, M. J. (2007) An observing system simulation experiment for the Indian Ocean. Journal of Climate, 20, 3300-3343.

27. Fujii, Y., Tsujino, H., Usui, N., Nakano H. \& Kamachi, M. (2008) Application of singular vector analysis to the Kuroshio large meander. Journal of Geophysical Research, 113(C07026), doi:10.1029/2007JC004476.

28. Le Henaff, M., De Mey, P. \& Marsaleix, P. (2009) Assessment of observational networks with the representer matrix specra method - application to a 3D coastal model of the Bay of Biscay. Ocean Dynamics, 59, 3-20.

29. Cardinala, C., Pezzulli, S. \& Andersson, E. (2004) Influence-matrix diagnostic of a data assimilation system, Quarterly Journal of the Royal Meteorological Society, 130, 2767-2786, doi:10.1256/qj.03.205.

30. Langland, R. H., \& Baker, N. L. (2004) Estimation of observation impact using the NRL atmospheric variational data assimilation adjoint system. Tellus, 56A, 189-201.

31. Benkiran, M., \& Greiner, E. (2007) Data assimilation of drifter velocities in the Mercator Océan system. Mercator Océan quarterly newsletter, 25, Available online at www.mercatorocean.fr/documents/lettre/lettre 25 en.pdf. 